\title{
Employing parent-teacher collaboration to enhance intrinsic motivation, creating a positive classroom climate and improved academic achievements In Arab School in Israel
}

\author{
Khaled Abu-Asbeh \\ Al-Qasemi Academy - Academic College of education \& Beit Berl College
}

\begin{abstract}
This study investigated ways in which intrinsic motivation can be enhanced to improve learning achievements and the correlation between motivation and classroom climate in an Arab public high school in Israel.187 school students in Grade 11 participated in the study which involved two main stages: (a) the investigation stage: examining the classroom climate, intrinsic motivation, sense of affiliation to the school, sense of wellbeing, and academic achievements in core disciplines, in addition to other relevant variables. (b) the implementation stage: this stage was performed with a set of workshops for teachers and parents over a period of six months, aimed at helping parents and teachers to improve the students' intrinsic motivation for learning. After the workshops, a questionnaire was administered for a second time to the students who had taken part in the investigation stage. Findings from the questionnaires revealed a positive correlation between students' level of achievements and the level of their intrinsic motivation, sense of belonging to the school and sense of wellbeing, and their perception of the classroom climate. All these components were found to have higher values among female students than among male students. It was concluded that the use of principles encouraging intrinsic motivation improved the level of the different components. Moreover, it was found that the use of these principles that encouraged intrinsic motivation only improved academic achievements among the male students, while among the female students the use of the same principles improved all the components.
\end{abstract}

Keywords: motivation, achievement, classroom climate, Arab School in Israel

\section{INTRODUCTION}

The school constitutes an important social setting for the child, in which he spends a significant part of his day. The school influences both behavioral patterns, the development of a selfimage and self-perception and these in turn influence the child's physical and mental wellbeing (Bond \& Compas, 1989; Coleman, 1979; Hurrelmann, Leppin \& Nordlohne 1995). The literature in this field indicates that the interaction between teachers and students influences the students' mental welfare. A normative relationship, support and student participation in decision-making all have a positive influence on students' academic and social behavior, expressed among other things in an improvement in the level of their academic achievements and a decrease in dropout rates (Garnefski, 1997), improving curiosity and scientific mastery (Birch \& Ladd, 1997), good relations between the students (Howes, Hamilton \& Matheson, 1994), and motivation for academic studies (Mendler, 2000) and producing a decrease in the rate of violent incidents, drug and alcohol consumption in the school (Resnick et al., 1997). The discussion on the school climate becomes significant due to the arguments of many educators that students do not have any motivation to learn. They depict a sense of alienation in the school. Staff burnout and students' sense of alienation can lead to an increase in cases of violence in the school as has been seen in Arab schools in Israel in recent years (Avner, 2014; Ronen, 2010; Marie-Alsana et al., 2006; Soen, 2002). This increase is often explained as the 
result of laxity in the value grounding on which the younger generation of society is built, especially in weakened social groups or minority groups (Hunt et al., 2002) or in multicultural societies (Webster, 2002). Under the basic assumption is that the problem lies in the lack of values and behavioral norms one of the solutions found for this problem is to inculcate a set of values, rules, and regulations that restrict the students' behavior. The present study suggests another viewpoint, arguing that the problem results from an insufficient extent of internalization of existing values and not necessarily their content. In this study, we attempt to investigate the link between two phenomena: the decrease in motivation and the unsatisfactory classroom climate, although it is more usual to connect these two phenomena in opposite order, i.e. an optimal classroom climate can increase motivation. In this context, our hypothesis is that activity performed out of the highest level of intrinsic motivation will improve the students' sense of wellbeing, increasing their sense of affiliation to the school and eventually improving the classroom climate and enhancing the students' academic achievements. An additional research question derived from the research process relates to the type of intervention used in the research. In this context, our hypothesis is that use of behavioral principles by parents and teachers to encourage intrinsic motivation will improve the students' level of motivation for their studies.

\section{CONCEPTUAL FRAMEWORK}

Despite abundant studies dealing with the subject of motivation, there has been no consensus regarding the definition of this term until now (Bar-Haim, 2002; Waugh, 2002). Bar-Haim (2002) defined motivation as a motivating force in activities performed out of will and accompanied by physical, intellectual and mental effort. Ashur (2001) defined motivation as a person's will to invest energies, resources and time to activities, even when the activity involves difficulties and lack of success. In contrast Thrash and Elliot (2001) saw motivation as a theoretical construct to explain the acts of people influenced by their needs and desires. A similar definition was suggested by Ball (1997) who saw motivation as a process that influences the arousal and continuation of people's behaviors. Organizational researchers added an additional element to the definition of the term "motivation" - personal benefit. They argue that motivation should be defined as the willingness to invest effort and energy in work in order to achieve organizational goals, while this willingness is influenced by social and economic exchange between the employee and the organization (Robbins, 2000).

Researchers have noted that there are different types of motivation including: intrinsic motivation and extrinsic motivation. The development of intrinsic motivation may stem from choice, pleasure or interest (Ryan and Deci, 2000).) In contrast, extrinsic motivation stems from a reward or fear of punishment (Vallerand et al., 1992). Some scholars have examined the influence of motivation on students' academic abilities (Graham \& Weiner, 1996; Pintrich \& Schunk, 2002). These scholars all noted that motivation is one of the factors that influence the running of the school and the atmosphere prevalent in the school and the extent of students' academic investment and achievements (Butzler, 2014; Tucker, Zayco, \& Herman, 2002). These studies show that there are several motivational factors that influence the extent of students' investment in their studies at school.

Apart from the motivational factors that influence students' academic achievements, many studies show that one of the most important variables influencing these achievements is the student's family's socio-economic status (Bornstein \& Bradley, 2003). This status is usually measured by the criteria of parents' education level and occupation; these two variables have been found to be the most significant predictors of children's academic achievements (Guo \& 
Harris, 2000). In addition to parents' education level, the literature indicates that the level of parents' involvement is also an important variable that has a positive influence contributing to their child's motivation and achievements (Brook \& Hancock, 2000; McNeal, 1999; Fan \& Chen, 2001).

In addition to the interest shown in motivation as a factor influencing the above-mentioned parameters, researchers have also investigated the classroom climate as a factor that can influence academic achievements. The classroom climate relates to the educational setting in which the students spend the main part of their day and it influences their experiences and behaviors, their self-image, self-confidence and personal development (Cheng, 1993). Research has studied the classroom as the place in which teaching and learning takes place and indicated several factors that influence these processes and their outputs (Fraser \& Walberg, 1991). These components include the school, students and teachers (Moos, 1979). According to Getzels and Thelen (1960), the class climate is influenced by the way in which the teacher balances demands with the personal needs of the class. Other studies have focused on the influence of the classroom climate on students' education and their academic achievements (Anderson, 1971; Haertel, Walberg \& Haertel, 1981), while some scholars focused on the teacher's leadership of the class (Wagner, 2001). These studies all indicate that the classroom climate can have a positive effect on the students' educational performances. A positive classroom climate improves academic achievements of all students including those from weak socio-cultural backgrounds such as most Arab students in Israel.

\section{School-parents relations}

The school's relationship with students' parents and the way in which the school perceives the parents involvement in the school is not self-evident. There are schools that see the parents' involvement as interference although other schools view them as a valuable resource. This latter perception can contribute to motivation for collaboration (Quiocho \& Daoud, 2006; Hoover-Demsey \& Sandler, 1997). One of the important factors for the success of the schoolparent relationship is the formation of trust. According to Adams, Forsyth and Miller (2009) trust is created through all school staff (management and teachers) with the parents. The existence of trust depends on organizational dimensions, i.e. organizational conditions and practices aimed at promoting coordination between the two sides. Adams, Forsyth and Miller (ibid.) claim that cooperation and a school climate that considers students' emotional needs will improve trust. True cooperation with parents indicates to the parents that the school values the role of the parents and their knowledge and positions the parents as valuable partners. This positioning facilitates openness, reliability and compassion, which are criteria for the construction of trust. The existence of trust improves the students' sense of belonging and security and guarantees their motivation for academic studies.

The involvement of parents/family in school activities helps to promote the students' educational processes, encouraging and mediating academic and social success (Fishel \& Ramirez, 2005). Jeynes (2007) noted the correlation between parents' involvement and academic successes of 32 students and showed that parental expectations were the best predictor for the student's success. Hattie (2005) and Hong and Ho (2009) found that if the parents' aspirations and expectations regarding their children's academic achievements were higher, then the students' expectations regarding their own performance were also higher and eventually also their achievements. A study conducted at the University of Illinois in Chicago (Patrikakou, 2004) found that parents' expectations had a significant influence on their children's academic achievements. 
Parents' cooperation with the school increases their children's motivation. According to Ecological Theory this motivation is also influenced by gender perceptions and cultural expectations regarding students' potential abilities. According to Lohman and Matjasko (2009) gender perceptions and cultural expectations are shaped by the students' home environment with its various components, the school environment and its components and the interaction between these two environments. Yet these components do not cancel out the influence of the student's personality that influences his sense of self-efficacy in both these settings. As far as could be ascertained, extant research literature has not related to gender differences in the influence of parents' involvement on students' achievements (Keith et al. 1998). It was however found that there was no difference in the type and strength of parents' involvement for both boys and girls. However, a study investigating the correlations between gender, school, home and the community (Sanders \& Herting, 2000) found that girls are awarded more support both at home and in school. The research literature also discusses the connection between parents' level of education and income, as a significant predictor of students' achievements (Guo \& Hartheris, 2000; Lee, 2002). Socio-economic status is also one of the most significant factors that explain the existence of academic gaps between different students, when they enter elementary school (Rumberger \& Anguiano, 2004; Wilson et al., 2002; Abbott \& Fouts, 2003).

There are studies that emphasize the influence of the education of both parents (Anderson \& Bruce, 2004) and others that especially emphasize the mother's education as significant predictors, and show that insofar as the student's mother has higher education, then they have a stronger probability of developing their child's cognitive skills and language skills, which are factors for their success in school in early years (Sticht \& McDonald, 1990).

According to the research literature, a low socioeconomic status is liable to be an accelerating factor for students' dropout from school (Janosz et al., 2000). Characteristics of lower socioeconomic strata such as multiple children, unemployment or low incomes etc. were found to correlate with the problems of dropout and low achievements (Englund, Egeland \& Collins, 2008).

Our research field was the Arab public high school. In this context it should be noted that the Arab population in Israel attributes significant importance to education as a major means for socio-economic mobility, both at the individual and the collective levels (Al-Haj, 1999; AbuAsbah, 2007). Those who have studied the Arab education system in Israel, claim that the system suffers from discriminatory allocation of resources. This inequality is expressed in the quality of teachers, the high number of students per class, the allocation of teaching hours, the lack of development of informal education etc. Thus it is easy to understand the low achievements of this system. This reality hinders the functioning of the Arab education system and makes it difficult for it to prepare its students for possible access to higher education as expected. This is expressed in lower academic achievements of the Arab education system in contrast to the Jewish education system, both in international exams and in local university entrance exams. It is noted that the most successful achievements in Arab education were recorded among girls and the increase in the number of Arab students in further education derives from the increase in female students (Abu-Asbah, 2005; Friedman Sokolor, 2015).

Despite the difficult conditions under which the Arab education system operates, and the difficulties for its functioning and outputs (academic achievements and behaviors) we would argue that correct work with skilled and well-trained human resources could help to improve 
this system and enhance its products. The present study examines the possibility of improving students' academic achievements through the improvement of students' intrinsic motivation with the help of both teachers and parents. The research focuses on the influence of students' intrinsic motivation on the classroom climate and the students' academic achievements, and the influence of the classroom climate on the improvement of students' achievements.

\section{METHODOLOGY}

The research aimed to investigate the influence of students' intrinsic motivation to learn on the classroom climate and on their academic achievements. For this purpose two research hypotheses were drafted:

Hypothesis 1: The participation of teachers and parents in workshops to encourage intrinsic motivation will improve the students' academic achievements, increase their intrinsic motivation and form a positive perception of the classroom climate among the students.

Hypothesis 2: Activities performed out of strong intrinsic motivation will increase the students' sense of wellbeing, improving their sense of belonging to the school and eventually enhance the classroom climate and improve the students' academic achievements.

\section{Research tools}

Data were collected with the help of a closed-ended questionnaire including 86 statements divided into six main parts, where each part examined a different variable and relied on an existing academic resource. These parts were:

1. A background questionnaire relating to the participants' gender, parents' income, and the family's socio-economic status.

2. The students' achievements in core disciplines: Hebrew, English, Mathematics and English.

Parts 3, 4, 5 and 6 of the questionnaire are described in Table 1 below:

Table 1: Parts 3, 4 and 5 of the questionnaire

\begin{tabular}{|l|l|r|r|c|}
\hline $\begin{array}{l}\text { The variable } \\
\text { Tested }\end{array}$ & $\begin{array}{l}\text { Questionnaire and } \\
\text { source }\end{array}$ & $\begin{array}{l}\text { Number of } \\
\text { items }\end{array}$ & Scale & $\begin{array}{l}\text { Cronbach's } \\
\boldsymbol{\alpha}\end{array}$ \\
\hline 3. The classroom climate & $\begin{array}{l}\text { Abbreviated } \\
\text { (Fraser 1989) }\end{array}$ & 27 & Likert & 0.750 \\
\hline $\begin{array}{l}\text { 4. Students' sense of } \\
\text { wellbeing }\end{array}$ & Kaplan \& Martin, 1999 & 9 & Likert & 0.830 \\
\hline $\begin{array}{l}\text { 5. Students' sense of } \\
\text { belonging to the school }\end{array}$ & Goodenow, 1993 & 18 & Likert & 0.862 \\
\hline 6. Intrinsic motivation & Harter, 1981 & 26 & Likert & 0.902 \\
\hline
\end{tabular}

\section{The research sample}

182 Arab high school students studying in Grade 12 from central Israel participated in the research. The schools were chosen because of the willingness and informed consent of the school management, teachers and parents to participate in the research.

\section{The research process}

The research was conducted in 2014 and lasted approximately one year. The choice of schools was determined after consultation with the Ministry of Education superintendent and after obtaining consent of the school teachers and parents for the performance of the research 
project in the school. Full confidentiality and anonymity was promised for participants in the presentation of the data.

The research consisted of two main stages: (a) the investigation stage - at this stage a questionnaire was administered to the students to examine the class climate, the students' intrinsic motivation, their sense of belonging to the school, their sense of wellbeing and academic achievements together with other relevant variables. (b) the intervention stage - this stage involved intervention by the research staff, expressed by providing workshops for parents and teachers. The workshops aimed to allow the participants to learn the principles of motivation in order to enhance parents' involvement in their children' life in school through activities together with the teachers and consequently improve the students' motivation. These activities aimed to improve coordination between the values, structures and practices in the school and those of the home. The program highlights actions and behaviors that the teachers and parents perform together in the school in order to improve the students' motivation, and consequently to provide support for their academic work (see in greater detail, Sheridan et al., 2012). At the end of this stage, the students again filled in the same questionnaire administered to them at the beginning of the research. The questionnaires were at both stages administered to the students in the classrooms where they studied by research assistants enlisted for this purpose. The questionnaires were translated into Arabic and students were given 45 minutes to complete them.

\section{DATA ANALYSIS}

Initially the distribution of data for each of the variables was analyzed by means and standard deviations and percentages. Thus too, correlations were calculated between the different research variables (academic achievements, classroom climate, sense of wellbeing, sense of belonging to the school and intrinsic motivation) with Pearson's correlation coefficients. Additionally, t-tests and one-way ANOVA tests were used to calculate the correlation between the dependent variables (academic achievements, classroom climate, sense of wellbeing, sense of belonging to the school and intrinsic motivation) and the background variables (gender, father's education, mother's education).

In addition, the research hypotheses were tested with a test of variance in the dependent variables (academic achievements, classroom climate, sense of wellbeing, sense of belonging to the school and intrinsic motivation) according to the independent variables (participation in the workshops and gender) using t-tests and also using path analysis. The statistical data were processed with the statistical software SPSS 20.

\section{Descriptive statistics}

\section{FINDINGS}

Initially factor analysis was conducted with CFA - Principal component with varimax rotation to test the internal structure of the research variables: intrinsic motivation, classroom climate, students' sense of wellbeing and sense of belonging to the school and comparison of this structure with the structure described in extant professional literature. The factor analysis divided the 27 items defining the variable 'classroom climate' into six factors: teachers' support, affiliation, belonging, order in the classroom, task orientation and involvement (loading range for the items: 0.383-0.742). In addition factor analysis divided the 9 items defining the variable "wellbeing" into one factor (loading range for the items: 0.479-0.845). Moreover, factor analysis divided the 18 items defining the variable "belonging to the school" into one factor (loading range for the items: 0.389-0.776). With regard to the variable "intrinsic 
motivation", factor analysis divided the 26 items defining this variable into four factors: challenge, curiosity, mastery and judgment (loading range for the items: 0.334-0.807). It is noted that the internal structure of the research variables is in line with the structure commonly noted in research literature.

Table 1 below presents the distribution of participants' demographic characteristics and the research variables. The data in the table indicate that the students' average academic achievements stood at 76.80. The students reported a medium-high level for the following variables: classroom climate $(M=3.16)$, sense of well-being $(M=3.69$, sense of belonging to the school $(M=3.78)$ and intrinsic motivation $(M=3.65)$.

Table 1: Distribution of participants' demographic characteristics and research variables

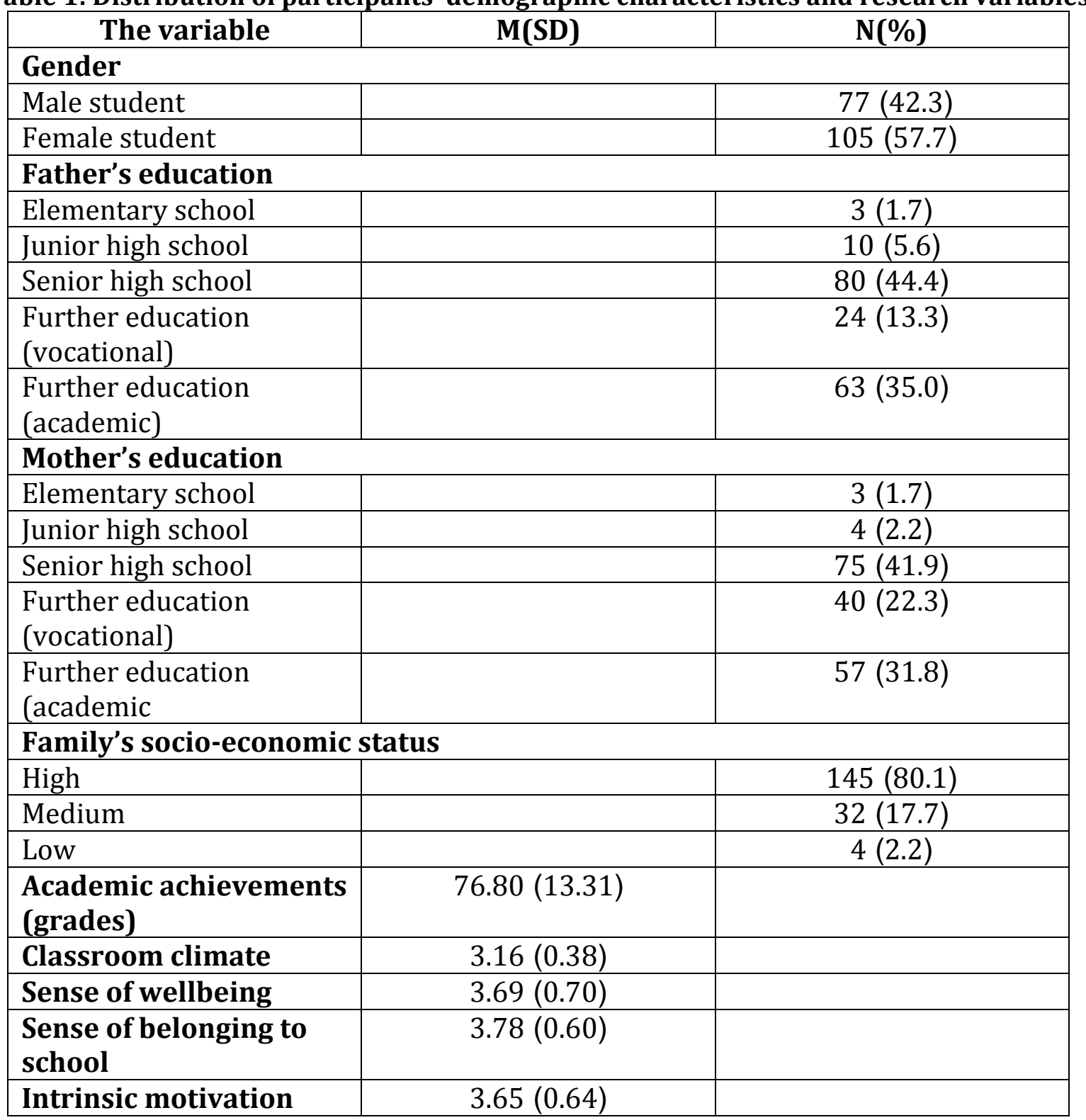

Table 2 displays the matrix of correlations between the variables: academic achievements, classroom climate, sense of wellbeing, sense of belonging to the school and intrinsic motivation. The table shows that the range of correlation values runs from a low correlation to a strong correlation (0.20-0.75). The data in the table indicate that there is a positive correlation between students' academic achievements and the variables classroom climate $(\mathrm{r}=$ 
0.27; $\mathrm{P}<0.001)$; sense of wellbeing $(\mathrm{r}=0.30 ; \mathrm{P}<0.001)$; sense of belonging to the school $(\mathrm{r}=$ $0.40 ; \mathrm{P}<0.001)$ and intrinsic motivation $(\mathrm{r}=0.20 ; \mathrm{P}<0.001)$. It was found that when the sense of wellbeing, the sense of belonging to the school, intrinsic motivation increased and the classroom climate was seen as positive by the students, then the level of students' academic achievements increased.

Table 2: Pearson's correlation coefficients for the research variables $(\mathrm{N}=182)$

\begin{tabular}{|l|c|c|c|c|}
\hline Variable & $\mathbf{1}$ & $\mathbf{2}$ & $\mathbf{3}$ \\
\hline $\begin{array}{l}\text { Academic } \\
\text { achievements }\end{array}$ & $0.27 * * *$ & & \\
\hline $\begin{array}{l}\text { Classroom } \\
\text { climate }\end{array}$ & $0.30 * * *$ & $0.57 * * *$ & & \\
\hline $\begin{array}{l}\text { Sense of } \\
\text { wellbeing }\end{array}$ & $0.40 * * *$ & $0.56^{* * *}$ & $0.75^{* * *}$ & \\
\hline $\begin{array}{l}\text { Sense of } \\
\text { belonging to } \\
\text { the school }\end{array}$ & $0.20^{* *}$ & $0.20^{* * *}$ & $0.55^{* * * *}$ & $0.54 * * *$ \\
\hline $\begin{array}{l}\text { Intrinsic } \\
\text { motivation }\end{array}$ & & & & \\
\hline
\end{tabular}

${ }^{* *} \mathrm{p}<0.01,{ }^{* * *} \mathrm{p}<0.001$

The influence of students' demographic characteristics on their intrinsic motivation, sense of wellbeing, sense of belonging to the school, classroom climate and academic achievements

Table 3 displays the results of t-tests performed for the non-paired samples to examine differences in the research variables between male and female students. The data in the table show that there was a significant statistical difference between the mean grade (index) for the four dimensions: academic achievements, sense of wellbeing, sense of belonging to the school and intrinsic motivation. It was found that the level of female students' academic achievements was higher than those of the male students. Moreover, the female students reported a higher sense of wellbeing, sense of belonging to the school, intrinsic motivation and positive perception of classroom climate than those of the male students. Values for the size of the effect for the significant differences were in the range medium-high 0.486 SD for academic achievements; 0.751 for sense of wellbeing; 0.998 for sense of belonging to the school and 0.824 SD for intrinsic motivation). 
Table 3: Means, standard deviations and t-values for non-paired samples to examine differences in the research variables between male and female students

\begin{tabular}{|l|c|c|c|c|c|c|c|}
\hline Variable & $\mathbf{N}$ & \multicolumn{2}{|c|}{$\begin{array}{c}\text { Female } \\
\text { students }\end{array}$} & \multicolumn{2}{|c|}{$\begin{array}{c}\text { Male } \\
\text { students }\end{array}$} & t & $\begin{array}{c}\text { Cohen's } \\
\mathbf{d}\end{array}$ \\
\hline & & $\mathbf{M}$ & $\mathbf{S D}$ & $\mathbf{M}$ & $\mathbf{S D}$ & & \\
\hline $\begin{array}{l}\text { Academic } \\
\text { achievements }\end{array}$ & 182 & 79.42 & 11.94 & 73.00 & 14.33 & $3.11^{\star *}$ & 0.486 \\
\hline Classroom climate & 182 & 3.21 & 0.41 & 3.11 & 0.33 & 1.71 & 0.269 \\
\hline Sense of wellbeing & 182 & 3.90 & 0.63 & 3.40 & 0.70 & $4.97^{\star \star *}$ & 0.751 \\
\hline $\begin{array}{l}\text { Sense of belonging to } \\
\text { the school }\end{array}$ & 182 & 4.01 & 0.51 & 3.47 & 0.57 & $6.67^{\star * *}$ & 0.998 \\
\hline Intrinsic motivation & 182 & 3.87 & 0.56 & 3.37 & 0.65 & $5.38^{\star * *}$ & 0.824 \\
\hline
\end{tabular}

** $\mathrm{p}<0.01,{ }^{* * *} \mathrm{p}<0.001$

Table 4 displays the results of $\mathrm{F}$ tests from one-way analysis of variance (ANOVA) examining differences in the research variables according to students' fathers' education. The data shown in the table indicate that there is a significant statistical difference according to level of father's education for the students' mean academic achievements. Significant differences between students were in favor of students whose fathers had academic education in comparison to students whose fathers had up to high school education ( $p<0.9=05$, Scheffe's post hoc test). The value for the size of the effect for the significant difference was low. Moreover, the data shown in the table indicate that no significant statistical difference was found between the mean grade (index) for the four dimensions: classroom climate, sense of wellbeing, sense of belonging to the school and intrinsic motivation.

Table 4: Means, standard deviations and $F$ values from the one-way analysis of variance (ANOVA) for differences in the research variables according to father's education (education up

to high school $\mathrm{N}=83$; vocational higher education $\mathrm{N}=22$; academic higher education $\mathrm{N}=58$ )

\begin{tabular}{|c|c|c|c|c|c|}
\hline Variable & Father's education & Mean & SD & $\mathbf{F}$ & $\mathbf{h} 2$ \\
\hline \multirow[t]{3}{*}{ Academic achievements } & Up to high school & 74.61 & 13.03 & \multirow{3}{*}{$3.573 *$} & \multirow{3}{*}{0.043} \\
\hline & Vocational higher education & 76.11 & 13.75 & & \\
\hline & Academic higher education & 80.54 & 12.83 & & \\
\hline \multirow[t]{3}{*}{ Classroom climate } & Up to high school & 3.11 & 0.33 & \multirow{3}{*}{2.07} & \multirow{3}{*}{0.023} \\
\hline & Vocational higher education & 3.14 & 0.34 & & \\
\hline & Academic higher education & 3.24 & 0.56 & & \\
\hline \multirow[t]{3}{*}{ Sense of wellbeing } & Up to high school & 3.70 & 0.65 & \multirow{3}{*}{1.81} & \multirow{3}{*}{0.020} \\
\hline & Vocational higher education & 3.45 & 0.69 & & \\
\hline & Academic higher education & 3.76 & 0.77 & & \\
\hline \multirow[t]{3}{*}{ Sense of belonging to school } & Up to high school & 3.76 & 0.52 & \multirow[t]{3}{*}{1.92} & \multirow[t]{3}{*}{0.021} \\
\hline & Vocational higher education & 3.63 & 0.64 & & \\
\hline & Academic higher education & 3.89 & 0.68 & & \\
\hline \multirow[t]{3}{*}{ Intrinsic motivation } & Up to high school & 3.72 & 0.60 & \multirow[t]{3}{*}{0.77} & \multirow[t]{3}{*}{0.009} \\
\hline & Vocational higher education & 3.56 & 0.54 & & \\
\hline & Academic higher education & 3.62 & 0.75 & & \\
\hline
\end{tabular}

$* \mathrm{p}<0.05$ 
Table 5 shows the results for the $\mathrm{F}$ tests from the one way analysis of variance (ANOVA) to examine differences in the research variables according to the students' mothers' level of education. The data in the table indicate that there is a significant statistical difference according to mother's level of education in relation to the students' academic achievements. Significant differences between the students were in favor of students whose mothers had academic education in contrast to students whose mothers had up to high school education and vocational higher education. The value for the size of the effect for the significant difference was low. Moreover, the data in the table show that no significant statistical difference was found between the mean grade (index) for the four dimensions: classroom climate, sense of wellbeing, sense of belonging to the school and intrinsic motivation.

Table 5: Means, standard deviations and $F$ values from the one-way analysis of variance (ANOVA) for differences in the research variables according to mother's education (education up to high school $\mathrm{N}=75$; vocational higher education $\mathrm{N}=37$; academic higher education $\mathrm{N}=50$ )

\begin{tabular}{|c|c|c|c|c|c|}
\hline Variable & Mother's education & Mean & SD & $\mathbf{F}$ & $\mathbf{h}_{2}$ \\
\hline \multirow{3}{*}{ Academic achievements } & Up to high school & 75.31 & 13.65 & \multirow{3}{*}{$3.793 *$} & \multirow{3}{*}{0.046} \\
\hline & Vocational higher education & 74.51 & 11.67 & & \\
\hline & Academic higher education & 81.14 & 13.18 & & \\
\hline \multirow[t]{3}{*}{ Classroom climate } & Up to high school & 3.16 & 0.38 & \multirow{3}{*}{0.109} & \multirow{3}{*}{0.001} \\
\hline & Vocational higher education & 3.14 & 0.28 & & \\
\hline & Academic higher education & 3.18 & 0.43 & & \\
\hline \multirow[t]{3}{*}{ Sense of wellbeing } & Up to high school & 3.68 & 0.70 & \multirow{3}{*}{1.037} & \multirow{3}{*}{0.012} \\
\hline & Vocational higher education & 3.58 & 0.72 & & \\
\hline & Academic higher education & 3.79 & 0.70 & & \\
\hline \multirow[t]{3}{*}{ Sense of belonging to school } & Up to high school & 3.78 & 0.57 & \multirow{3}{*}{0.838} & \multirow{3}{*}{0.009} \\
\hline & Vocational higher education & 3.70 & 0.62 & & \\
\hline & Academic higher education & 3.86 & 0.64 & & \\
\hline \multirow[t]{3}{*}{ Intrinsic motivation } & Up to high school & 3.64 & 0.65 & \multirow{3}{*}{1.654} & \multirow{3}{*}{0.018} \\
\hline & Vocational higher education & 3.53 & 0.62 & & \\
\hline & Academic higher education & 3.77 & 0.66 & & \\
\hline
\end{tabular}

$* \mathrm{p}<0.05$

Table 6 below displays the results of the $\mathrm{F}$ tests from the one-directional analysis of variance (ANOVA) to identify differences in the research variables according to the level of the student's academic achievements. The data shown in the table indicate that there was a significant statistical difference according to the mother's level of education with regard to the students' mean grade (index) for four dimensions: school climate, sense of wellbeing, sense of belonging to the school and intrinsic motivation. Analysis of the significant differences reveals that students with higher academic achievements report a more positive impression of the class climate than students who had lower academic achievements $(\mathrm{p}<0.05$ Scheffe's post hoc test). It was also found that students with lower academic achievements reported a lower sense of wellbeing than did students with medium academic achievements $(\mathrm{p}<0.05$ Scheffe's post hoc test) and those with high academic achievements ( $p<0.01$ Scheffe's post hoc test) With regard to the students' sense of belonging to the school, the findings indicate that students with high academic achievements reported a stronger sense of belonging to the school than students with medium academic achievements $(\mathrm{p}<0.01$ Scheffe's post hoc test) and those with low academic achievements ( $\mathrm{p}<0.001$ Scheffe's post hoc test). Moreover it was found that students with medium level academic achievements reported a higher level of intrinsic motivation in comparison to students with lower academic achievements $(\mathrm{p}<0.05$ Scheffe's post hoc test). 
Values for size of the effect for the significant differences were in the range low-high (low: intrinsic motivation; medium: classroom climate and sense of wellbeing; high: sense of belonging to the school).

Table 6: Means, standard deviations and $F$ values from the one-way analysis of variance (ANOVA) for differences in the research variables according to level of students' academic achievements (low $\mathrm{N}=75$; medium $\mathrm{N}=37$; high $\mathrm{N}=50$ ) ${ }^{1}$

\begin{tabular}{|c|c|c|c|c|c|}
\hline Variable & Mother's education & Mean & SD & $\mathbf{F}$ & $\mathbf{h}_{2}$ \\
\hline \multirow{3}{*}{ Classroom climate } & Low & 3.01 & 0.33 & \multirow{3}{*}{$5.153 * *$} & \multirow{3}{*}{0.061} \\
\hline & Medium & 3.12 & 0.38 & & \\
\hline & High & 3.28 & 0.39 & & \\
\hline \multirow[t]{3}{*}{ Sense of wellbeing } & Low & 3.31 & 0.69 & \multirow{3}{*}{$6.366 * *$} & \multirow{3}{*}{0.074} \\
\hline & Medium & 3.70 & 0.71 & & \\
\hline & High & 3.88 & 0.65 & & \\
\hline \multirow[t]{3}{*}{ Sense of belonging to school } & Low & 3.47 & 0.47 & \multirow{3}{*}{$11.224 * * *$} & \multirow{3}{*}{0.124} \\
\hline & Medium & 3.73 & 0.62 & & \\
\hline & High & 4.07 & 0.51 & & \\
\hline \multirow[t]{3}{*}{ Intrinsic motivation } & Low & 3.38 & 0.60 & \multirow{3}{*}{$3.867 *$} & \multirow{3}{*}{0.046} \\
\hline & Medium & 3.75 & 0.66 & & \\
\hline & High & 3.74 & 0.60 & & \\
\hline
\end{tabular}

${ }^{*} \mathrm{p}<0.05,{ }^{* *} \mathrm{p}<0.01,{ }^{* * *} \mathrm{p}<0.001$

The influence of intrinsic motivation on academic achievements, sense of wellbeing, classroom climate and sense of belonging to the school

Table 7 below displays the findings relating to the influence of the use of principles encouraging intrinsic motivation (training courses for teachers and parents) on the research variables. The findings indicate that the gap between the four dimensions: academic achievements, classroom climate, sense of wellbeing and sense of belonging to the school, according to participation in the courses for the improvement of intrinsic motivation, is statistically significant. It was found that participation in the courses increased the students' mean academic achievements, their sense of wellbeing, sense of belonging to the school and their positive perception of the classroom climate. The values for the size of the effect for the significant differences were in the range of medium-high $(2.017$ SD for academic achievements; 0.666 for classroom climate; 0.563 for sense of wellbeing and 0.873 SD for sense of belonging to the school).

\footnotetext{
1 To test the differences in the research variables according to the students' level of academic achievements, the variable "academic achievement" was recreated: a mean grade of 0-64 was encoded as low; 65-84 was encoded as medium and 85-100 was encoded as high.
} 
Table 7: Means, standard deviations and $t$ values for non-paired samples to test differences in the research variables between male and female students before and after the courses

\begin{tabular}{|l|c|c|c|c|c|c|c|}
\hline \multirow{2}{*}{ Variable } & \multirow{2}{*}{$\mathbf{N}$} & \multicolumn{2}{c|}{$\begin{array}{c}\text { Before the } \\
\text { course }\end{array}$} & \multicolumn{2}{c|}{$\begin{array}{c}\text { After the } \\
\text { course }\end{array}$} & \multirow{2}{*}{ T } & \multirow{2}{*}{$\begin{array}{c}\text { Cohen' } \\
\text { s d }\end{array}$} \\
\cline { 3 - 7 } & & Mean & SD & Mean & SD & & 2.017 \\
\hline $\begin{array}{l}\text { Academic } \\
\text { achievements }\end{array}$ & $\mathbf{1 8}$ & 67.57 & 9.57 & 86.48 & 9.17 & $12.90 * * *$ & \\
\hline Classroom climate & $\mathbf{1 8}$ & 3.04 & 0.36 & 3.28 & 0.36 & $4.42 * * *$ & 0.666 \\
\hline Sense of wellbeing & $\mathbf{1 8}$ & 3.49 & 0.68 & 3.87 & 0.67 & $3.81 * * *$ & 0.563 \\
\hline $\begin{array}{l}\text { Sense of belonging } \\
\text { to school }\end{array}$ & $\mathbf{1 8}$ & 3.53 & 0.55 & 4.01 & 0.55 & $5.84 * * *$ & 0.873 \\
\hline Intrinsic motivation & $\mathbf{1 8}$ & 3.59 & 0.63 & 3.72 & 0.66 & 1.32 & -0.201 \\
\hline
\end{tabular}

$* * * \mathrm{p}<0.001$

Table 8 below shows the results of t-tests for the paired samples to test for differences I the research variables among male students before the courses were conducted and after they ended. The data shown in the tables show that there is a significant statistical difference between the mean grade (index) of three dimensions: academic achievements, sense of wellbeing and sense of belonging to the school. It was found that the courses appeared to increase the students' mean academic achievements, sense of wellbeing and sense of belonging to the school. Values for the size of the effect for significant differences were in the range of medium-high (2.271 SD for academic achievements; 0.503 for sense of wellbeing and $0.932 \mathrm{SD}$ for sense of belonging to the school).

Table 8: Means, standard deviations and $t$ values for non-paired samples to test differences in the research variables between male students before and after the courses

\begin{tabular}{|l|c|c|c|c|c|c|c|}
\hline \multirow{2}{*}{ Variable } & \multirow{2}{*}{$\mathbf{N}$} & \multicolumn{2}{c|}{$\begin{array}{c}\text { Before the } \\
\text { course }\end{array}$} & \multicolumn{2}{c|}{$\begin{array}{c}\text { After the } \\
\text { course }\end{array}$} & \multirow{2}{*}{ T } & \multirow{2}{*}{ Cohen's d } \\
\cline { 3 - 7 } & & Mean & SD & Mean & SD & & \\
\hline $\begin{array}{l}\text { Academic } \\
\text { achievements }\end{array}$ & 182 & 63.68 & 9.98 & 85.22 & 8.96 & $9.14^{* * *}$ & 2.271 \\
\hline Classroom climate & 182 & 3.07 & 0.34 & 3.15 & 0.32 & 1.06 & 0.242 \\
\hline Sense of wellbeing & 182 & 3.24 & 0.68 & 3.58 & 0.67 & $2.24 *$ & 0.503 \\
\hline $\begin{array}{l}\text { Sense of belonging } \\
\text { to school }\end{array}$ & 182 & 3.24 & 0.51 & 3.72 & 0.52 & $4.05^{* * *}$ & 0.932 \\
\hline Intrinsic motivation & 182 & 3.30 & 0.61 & 3.45 & 0.68 & 1.01 & 0.232 \\
\hline
\end{tabular}

${ }^{*} \mathrm{p}<0.05,{ }^{* * *} \mathrm{p}<0.001$

Table 9 below shows the results of t-tests for paired samples to test differences in the research variables among the female students before and after the courses. The data in the table show that there is a significant statistical difference between the mean grade (index) for four dimensions: academic achievements, classroom climate, sense of wellbeing and sense of belonging to the school. It was found that the courses appeared to increase the female students' mean academic achievements, sense of wellbeing, sense of belonging to the school and their positive perception of the class climate. The values for the size of the effect for the significant differences were in the range of medium-high $(1.894 \mathrm{SD}$ for academic 
achievements; 0.933 for classroom climate; 0.574 for sense of wellbeing and 0.893 for sense of belonging to the school).

Table 9: Means, standard deviations and $t$ values for non-paired samples to test differences in the research variables between female students before and after the courses

\begin{tabular}{|l|c|c|c|c|c|c|c|}
\hline \multirow{2}{*}{ Variable } & \multirow{2}{*}{$\mathbf{N}$} & \multicolumn{2}{c}{$\begin{array}{c}\text { Before the } \\
\text { course }\end{array}$} & \multicolumn{2}{c|}{$\begin{array}{c}\text { After the } \\
\text { course }\end{array}$} & \multirow{2}{*}{ T } & \multirow{2}{*}{ Cohen's d } \\
\cline { 3 - 7 } & & Mean & SD & Mean & SD & & \\
\hline $\begin{array}{l}\text { Academic } \\
\text { achievements }\end{array}$ & $\mathbf{1 8 2}$ & 70.79 & 7.98 & 87.21 & 9.30 & $9.35 * * *$ & 1.894 \\
\hline Classroom climate & $\mathbf{1 8 2}$ & 3.01 & 0.38 & 3.36 & 0.37 & $4.69 * * *$ & 0.933 \\
\hline Sense of wellbeing & $\mathbf{1 8 2}$ & 3.71 & 0.61 & 4.06 & 0.61 & $2.97 * *$ & 0.574 \\
\hline $\begin{array}{l}\text { Sense of belonging } \\
\text { to school }\end{array}$ & $\mathbf{1 8 2}$ & 3.78 & 0.45 & 4.20 & 0.49 & $4.49 * * *$ & 0.893 \\
\hline Intrinsic motivation & $\mathbf{1 8 2}$ & 3.84 & 0.54 & 3.89 & 0.59 & 0.45 & 0.088 \\
\hline
\end{tabular}

$* * \mathrm{p}<0.01,{ }^{* * *} \mathrm{p}<0.001$

\section{Influence of intrinsic motivation, sense of wellbeing, sense of belonging to the school} and classroom climate on students' academic achievements

In order to test the model presented in the second research hypothesis, Path Analysis was performed. The model included the following pathways: (a) intrinsic motivation to sense of wellbeing (b) intrinsic motivation to sense of belonging to the school (c) sense of wellbeing and belonging to the school to classroom climate (d) classroom climate to academic achievements (see Figure 1 below).

Figure 1: Path analysis with standard Standardized: intrinsic motivation, sense of wellbeing, sense of belonging to the school, classroom climate and academic achievements



It can be seen from Figure 1 that all the paths were significant. It was found that intrinsic motivation significantly predicted a sense of wellbeing $(0.55 ; \mathrm{p}<0.001)$ and sense of belonging to the school. It was also found that the classroom climate significantly predicted a sense of wellbeing $(0.33 ; \mathrm{p}<0.001)$ and a sense of belonging to the school. Moreover, it was found that the classroom climate was significantly predicted by the sense of wellbeing $(0.35 ; \mathrm{p}<0.01)$. It 
was also found that the students' academic achievements correlated positively with the classroom climate $(0.27 ; \mathrm{p}<0.001)$. These findings support the second research hypothesis.

\section{DISCUSSION}

The purpose of this study was to examine the influence of the classroom climate on an improvement in the students' academic achievement and the correlation between students' intrinsic motivation and classroom climate.

The findings first described the demographic characteristics of the students. It appeared that the values for all the components (academic achievements, sense of wellbeing, sense of belonging to the school, intrinsic motivation and positive perception of the classroom climate) were higher among the female students than among the male students. These findings are not surprising in light of recent educational research and statistics that the higher educational achievements of female students as a fact (Abu-Asbah, 2011; Friedman Sokolor, 2015). Moreover the finds indicate the existence of a correlation between parents' level of education and achievements of both male and female students. This finding is in line with other research findings on this issue (Abbott \& Fouts, 2003; Rumberger \& Anguiano, 2004; Wilson et al., 2002), thus too the mother's education level is significant for students achievements (Sticht \& McDonald, 1990). It was also found that the students' families socio-economic status influenced their academic achievements, this finding is supported by findings of similar studies in other countries (Jamosz et al., 2000), especially among families with characteristics of low socio-economic strata such as many children in the family, unemployment or low income (Englund, Egeland \& Collins, 2008). This picture is especially reflected in Arab society in Israel, which suffers from a low socio-economic status (Central Bureau of Statistics, Announcement to the Press, 2016) ${ }^{2}$.

The findings confirm the first hypothesis that the participation of teachers and parents in workshops to encourage intrinsic motivation will improve the students' academic achievements, increase their intrinsic motivation and form a positive perception of the classroom climate among the students. The findings indicate that the application of principles that enhance intrinsic motivation (through courses for parents and teachers) improved the students' academic achievements, their sense of wellbeing, sense of belonging to the school and positive perception of the classroom climate. These findings resemble reports in the relevant literature concerning the importance of parents' involvement (Fishel \& Ramirez, 2005; Hill \& Tyson, 2009) and the very presence of parents as partners, and their belief in, and expectations in regard to their children's abilities as important variables for the improvement of the children's academic achievements (Hattie, 2009; Hong \& Ho, 2005). In addition, it was found that cooperation between the school staff and the parents, can act as a factor improving the level of the children's motivation. Nevertheless, this motivation, according to Ecological Theory is influenced by gender perceptions and cultural expectations regarding the children's abilities. Scholars have noted that during parent-teacher workshops trust is formed between the school and the parents, and this has implications for the children's feelings and reinforces their motivation for academic studies (Adams, 2009; Lohman and Matjasko, 2009).

The perception of the parents as a resource by the school management and teachers can improve the motivation for the development of a partnership between them (Quiocho \& Daoud, 2006; Hoover-Demsey \& Sandler, 1997).

2 http://www.cbs.gov.il/reader/newhodaot/hodaa_template.html?hodaa=201611279 
The findings also confirm the second research hypothesis that activities performed out of strong intrinsic motivation will increase the students' sense of wellbeing, improving their sense of belonging to the school and eventually enhance the classroom climate and improve the students' academic achievements. The findings show a significant correlation between the following variables:

- Intrinsic motivation was significantly associated with the sense of wellbeing and sense of belonging to the school

- The classroom climate was significantly predicted by the sense of wellbeing and sense of belonging to the school.

- Students' academic achievements correlated positively with the classroom climate

- Improvement of students' intrinsic motivation led to students' improved sense of wellbeing, enhanced their sense of belonging to the school and eventually improved the classroom climate and improved students' academic achievements.

This study constitutes a pioneer research in this direction-changing field of study, since it sees classroom climate as a motivational factor and envisages that motivation can be improved initially through a collaborative action of teachers and parents, thus causing an improvement in the students' sense of wellbeing and sense of belonging to the school and the classroom and producing an optimal classroom climate.

\section{References}

Abbott, M. L \& ,Fouts, J. T. (2003). Constructivist teaching and student achievement: The results of a school-level classroom observation study in Washington .Retrieved from Washington School Research Center Web site : www.spu.edu/wsrc/ObservationStudy-2-13-03.pdf

Abu-Asbah, K. (2005). The educational achievements of female Arab students in Israel as a factor in entering the job market and an opportunity to change their social status. In E. Paldi (Ed.). Education in the Test of Time 2 (pp. 627-646). Tel Aviv: Reches Publishers. [Hebrew]

Abu-Asbah, K. (2007). The Arab Educational System in Israel: Dilemmas of a National Minority. Jerusalem: The Floersheimer Institute for Policy Research. 156 pages. [Hebrew]

Adams C., Forsyth P. \& Mitchell R. (2009). The formation of parent-school trust: A multilevel analysis. Educational Administration Quarterly, 45, 4-33.

Al-Haj, M. (1999). Higher education among Arabs in Israel. Haifa: University of Haifa. [Hebrew]

Anderson, C. A., \& Bruce, C. J. (2004). Using family background to predict educational attainment in Canada, Economica LTD., The Expert Witness Newsletter, 9 (3).

Anderson, G.J. (1971). Effects of course content and teacher's sex on the social climate of learning. American Educational Research, 8(4), 649-663.

Ashur, A. (2001). Fostering intrinsic motivation for school learning. In A. Kaplan \& A. Ashur (Eds.) Education for thinking: Motivation for learning. New Approaches to Motivation, 20, (pp. 167-190). Jerusalem: Branko Weiss Institute. [Hebrew]

Avner, A. (2014). Violence towards teachers in Israel. Jerusalem: The Knesset Center for Research and Information. [Hebrew]

Ball, Samuel (1977). Motivation in education. Princeton, New Jersey: Educational Testing service, New York - San Francisco: Academic Press,

Bar-Haim (2002). The open university. Organizational Behavior, 1(4), 191-245. [Hebrew]

Birch, S.H., \& Ladd, G.W. (1997). The teacher-child relationship and children's early school adjustment. Journal of School Psychology, 35(1), 61-79

Bond, L. \& Compas, B. (Eds.). (1989). Primary prevention and promotion in the schools. Newbury Park, CA: Sage Publications, Inc. 
Bornstein, M. H., \& Bradley, R. H. (2003). Socioeconomic status, parenting, and child development. Mahwah, NJ: Lawrence Erlbaum Associates.

Brook, D., \& Hancock, R. (2000). “What Are parent-school organizations for? Some views from an Inner London LEA," Educational Review 52, 259-267.

Butzler, Kelly B. (2014). The effects of motivation on achievement and satisfaction in a flipped classroom learning environment. Prescott Valley, Arizona: ProQuest LLC.

Cheng, Y. C. (1993). An investigation of the relationship between classroom environment and students' affective performance. Paper presented at the Annual Conference of the American Educational Research Association, Atlanta, G.A.

Coleman, J. C. (1979). The school years: Current issues in the socialization of young people. London: Methuen.

Englund, M.M., Egeland, B. \& Collins, W.A. (2008). Exceptions to high school dropout predictions in a low-income sample: Do adults make a difference. Journal of Social Issues, 64(1), 77-94.

Fan, X., \& Chen, M. (2001). Parental involvement and student's academic achievement: A meta-analysis," Educational Psychology Review 13, 1-22.

Felix, E. D., Furlong, M. J., \& Austin, G. (2009). A cluster analytic investigation of school violence victimization among diverse students. Journal of Interpersonal Violence, 24(10),1673-1695.

Fishel, M., \& Ramirez, L. (2005). Evidence-based parent involvement interventions with schoolaged children. School Psychology Quarterly, 20, 371-402.

Fraser, B. J., \& Walberg, H. J. (1991). Education Environment: Evaluation, Antecedents and Consequences. Oxford: Pergamon Press.

Fraser B.J. (1989). Assessing and improving classroom environment. In What research says to the science and mathematics teacher (No. 2). Perth, Australia: Curtin University of Technology, Key Centre for School Science and Mathematics.

Friedman Sokolor, N. (2015). Sector and gender: A gender-related view of gaps in matriculation exam achievements between Arab and Hebrew education students. Economics and Society, 19. Jerusalem: Van Leer Institute. [Hebrew]

Garnefski, N. (1997). Emotional and behavioral problems in adolescence: Prevalence and risk factors of comorbidity. Thesis, Leiden-Collage. Van Dekanen.

Getzels, J.W., \& Thelen, H.A. (1960), The classroom as a unique social system. The 59th Yearbook of the National Society for the Study of Education (part 2,pp. 53-82)

Goodenow, C. (1993). The psychological sense of school membership among adolescents: Scale development and educational correlates. Psychology in Schools 30, 79-90.

Graham, S., \& Weiner, B. (1996). Theories and principles of motivation. In D. C. Berliner \& R. Calfee (Eds.), Handbook of educational psychology (pp. 63-84). New York: Macmillan.

Guo, G., and K. M. Harris, 2000. “The Mechanisms Mediating the Effects of Poverty on Children's Intellectual Development,” Demography 37, pp. 431-447.

Kaplan, A. \& Maehr, M. (1999). Enhancing the Motivation of African American Students: An Achievement Goal Theory Perspective, Contemporary Educational Psychology, Volume 24, Issue 4, Pages 330-358.

Hattie, J., (2009), Visible learning: A synthesis over 800 meta-analysis relating to achievement, London: Routledge Haertel, G. D., Walberg, H. J. \& Haertel, E. H. (1981). Socio-Psychological environments and learning: A quantitative synthesis. British Educational Research Journal, 7, 27-36.

Harter, S. (1981). A new self-report scale of intrinsic versus extrinsic orientation in the classroom: Motivational and informational components. Developmental Psychology, 17, 300-312.

Hill N. \& Tyson D. (2009). Parental involvement in middle school: A meta-analytic assessment of the strategies that promote achievement, Developmental Psychology 45(3), 740-763.

Hong, S. \& Ho, H.Z. (2005). Direct \& indirect longitudinal effects of parental involvement on student achievement: Second-order latent growth modeling across ethnic groups. Journal of Educational Psychology, 97(1), 32-42. 
Abu-Asbeh, K. (2017). Employing parent-teacher collaboration to enhance intrinsic motivation, creating a positive classroom climate and improved academic achievements In Arab School in Israel. Advances in Social Sciences Research Journal, 4(8) 42-59.

Hoover-Dempsey, K.V., \& Sandler, H.M. (1997) Why do parents become involved in their children's education? Review of Educational Research, 67, 1, 3-42.

Hurrelmann, K., Leppin, A., \& Nordlohne, E. (1995). Promoting health in schools: The German example. Health Promotion International, 10, 121-131.

Howes, C., Hamilton, C.E., \& Matheson, C.C. (1994). Children's relationships with peers: Differential association with aspects of the teacher-child relationship. Child Development, 65, 253-263.

Hunt, H., Meyers, M. Davies, J., Meyers G., Rogers, B., Grogg, K., \& John, N. (2002), A comprehensive needs assessment to facilitate prevention of school drop out and violence. Psychology in the Schools, 39(4), 399-416. Georgia State University.

Janosz, M., Le Blanc, M., Boulerice, B. \& Tremblay, R. E. (2000). Predicting different types of school dropouts: A typology approach with two longitudinal samples. Journal of Educational Psychology, 92, 171-190.

Jeynes W.H. (2007). The relationship between parental involvement \& urban secondary school student academic achievement: A meta-analysis. Urban Education, 42, 82-110.

Keith, T. Z., Keith, P. B., Quirk, K. J., Sperduto, J., Santillo, S., \& Killings, S. (1998). Longitudinal effects of parent involvement on high school grades: Similarities \& differences across gender \& ethnic groups. Journal of School Psychology, 36(3), 335-363.

Lee, Jaekyung .2002 .Racial and ethnic achievement gap trends: Reversing the progress toward equity? Educational Researcher 31.123 ,

Lohman B.J. \& Matjasko J.L. (2009). Creating school family partnerships in adolescence: Challenges \& opportunities. In In S. L. Christenson \& A. L. Reschly (Eds.), Handbook of School-Family Partnerships (pp. 3-29). New York, NY: Routledge.

Marie-Alsana , W., Haj-Yahia, M. \& Greenbaum, C. (2006). Violence among Arab elementary school pupils in Israel. Journal of Interpersonal Violence, 21(1), 58-88

McNeal, R. B. (1999). Parental involvement as social capital: Differential effectiveness on science achievement, truancy, and dropping out, Social Forces, 78, 117-144.

Mendler, A. (2000). Motivating students who don't care. Bloomington, IN: National Education Service.

Moos. R.N. (1979), Evaluating educational environments. San Francisco: Jossey-Bass, Inc.

Quiocho, A. M. L., \& Daoud, A. M. (2006). Dispelling myths about Latino parent participation in schools. The Educational Forum, 70(3), 255-267.

Patrikakou, E. N (2004). Where adolescence: Are parents relevant to students' high school achievement and postsecondary attainment? Retrieved from: Harvard Family Research Project Website:

http://www.gse.harvard.edu/hfrp/projects/fine/resources/digest/adolescence.html

Pintrich, P. R., \& Schunk, D. (2002). Motivation in education: Theory, research, and applications (2nd ed.). Upper Saddle, NJ: Prentice-Hall, Inc.

Resnick, M.D. et al. (1997). Protecting adolescents from harm: findings from the National Longitudinal Study on Adolescent Health. Journal of the American Medical Association, 27 (10), 823-832.

Robbins, S.P. (2000). Essentials of organizational behavior (6th ed.). Engelwood Cliffs. N.J.: Prentice- Hall.

Ronen, I. (2010). Statistics on crime in Arab society in Israel. Jerusalem: The Knesset Center for Research and Information. [Hebrew]

Rumberger, R. W., \& Anguiano, B. A. (2004). Understanding and addressing the California Latino achievement gap in early elementary school .Retrieved from http://lmri.ucsb.edu/publications/04_rumberger-arellano.pdf

Ryan, R. M., \& Deci, E. L. (2000). Self-determination theory and the facilitation of intrinsic motivation, social development, and well being. American Psychologist, 55, 68-78.

Sanders, M. \& Herting, R. (2000), Gender and the effects of school, family, and church support on the academic achievement of African-American urban adolescents. In Mavis G. Sanders (Ed.), Schooling students placed at risk: Research, policy, and practice in the education of poor and minority adolescents, Mahwah, NJ: Lawrence Erlbaum Associates, 141-161 
Sheridan, S. M., Kim, E. M., Coutts, M. J., Sjuts, T. M., Holmes, S. R., Ransom, K. A. \& Garbacz, S. A.(2012). Clarifying parent involvement \& family-school partnership intervention research: A preliminary synthesis. CYFS Working Paper No. 2012-4.

Soen, D. (2002). School violence and its prevention in Israel International Education Journal, 3(3).

Sticht, T. G \& ,.McDonald, B.A. (1990). Teach the mother and reach the child: Literacy across generations .Literacy Lessons. Geneva: International Bureau of Education.

Thrash, T. M., \& Elliot, A. J. (2004). Inspiration: Core characteristics, component processes, antecedents, and function. Journal of Personality and Social Psychology, 87, 957-973

Thrash, T. M., \& Elliot, A. J. (2004). Inspiration: Core characteristics, component processes, antecedents, and function. Journal of Personality and Social Psychology, 87, 957-973

Thrash, T. M., \& Elliot, A. J. (2004). Inspiration: Core characteristics, component processes, antecedents, and function. Journal of Personality and Social Psychology, 87, 957-973

Thrash, T. M., \& Elliot, A. J. (2004). Inspiration: Core characteristics, component processes, antecedents, and function. Journal of Personality and Social Psychology, 87, 957-973

Thrash,T.M \& Elliot, A.J. (2001). Delimiting and integrating achievement motive and goal constructs. In Elfklides, Kuhl and Sorrentino (Eds.), Trends and Prospects in Motivation Research. Netherlands: Kluwer Academic Publishers, 3-22.

Tucker, C. M., Zayco, R. A., \& Herman, K. C. (2002). Teacher and child variables as predictors of academic engagement among low-income African American children. Psychology in the Schools, 39(4), 477-488.

Vallerand, R. J., Pelletier, L. G., Blais, M. R., Briere, N. M., Senecal, C., \& Vallieres, E. F. (1992). The Academic Motivation Scale: A measure of intrinsic, extrinsic and motivation in education. Educational and Psychological Measurement, 52, 1003-1017.

Walberg, H.J. (1968). Teacher personality and classroom climate. Psychology in the Schools, 5, 163-169.

Wagner, T., 2001. Leadership for Learning: An Action Theory of School Change, Phi Delta Kappan 82, $378-383$.

Waugh, R. F. (2002). Creating a scale to measure motivation to achieve academically: Linking attitudes and behaviors using Rasch measurement. British Journal of Educational Psychology, 72, 65-86.

Webster Y. O. (2002), A human-centric alternative to diversity and multicultural education. Journal of Social Work Education, 38(1), 17-36. California State University, Los Angeles.

Wilson, B ,.Abbott, M., Joireman, J., \& Stroh, H. (2002). The relations among school environment variables and student achievement: A structural equation modeling approach to effective schools research .Technical Report \#4. Lynnwood, WA :Washington School Research Center, Seattle Pacific University. 